\title{
BMJ Open Does prewarming the i-gel supraglottic airway device fit the larynx better compared to keeping it at room temperature for non-paralysed, sedated patients: a randomised controlled trial
}

\author{
Nobuyasu Komasawa, ${ }^{1}$ Isao Nishihara, ${ }^{2}$ Shinichi Tatsumi, ${ }^{1}$ Toshiaki Minami ${ }^{1}$
}

To cite: Komasawa N, Nishihara I, Tatsumi S, et al. Does prewarming the i-gel supraglottic airway device fit the larynx better compared to keeping it at room temperature for nonparalysed, sedated patients: a randomised controlled trial. BMJ Open 2015;5:e006653. doi:10.1136/bmjopen-2014006653

- Prepublication history for this paper is available online. To view these files please visit the journal online (http://dx.doi.org/10.1136/ bmjopen-2014-006653).

Received 16 September 2014 Revised 26 December 2014 Accepted 29 December 2014

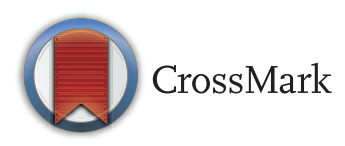

${ }^{1}$ Department of Anaesthesiology, Osaka Medical College, Takatsuki, Osaka, Japan

${ }^{2}$ Department of

Anaesthesiology, Hokusetsu General Hospital, Takatsuki, Osaka, Japan

Correspondence to Dr Nobuyasu Komasawa; ane078@poh.osaka-med.ac.jp

\section{ABSTRACT}

Objective: This study aimed to test the hypothesis that the i-gel supraglottic airway device would fit the larynx and provide better sealing pressure if prewarmed to $42^{\circ} \mathrm{C}$ relative to the device kept at room temperature in non-paralysed, sedated patients.

Methods: A total of 74 adult patients were assigned to the warm (i-gel prewarmed to $42^{\circ} \mathrm{C}$; W group; 37 patients) or the control (i-gel kept at room temperature; C group; 37 patients) groups. Anaesthesia was induced with propofol and fentanyl. The i-gel was prewarmed to $42^{\circ} \mathrm{C}$ for 30 min before insertion in the $\mathrm{W}$ group, but kept at room temperature (approximately $23^{\circ} \mathrm{C}$ ) for the $\mathrm{C}$ group. The number of attempts made until successful insertion and sealing pressure were compared between the two groups.

Results: Insertion was successful with one attempt in 35 cases each for the $\mathrm{W}$ and $\mathrm{C}$ groups. Two attempts were needed in two cases for the $\mathrm{W}$ group and one case for the $\mathrm{C}$ group. There was one failed attempt in the $\mathrm{C}$ group, but none in the $\mathrm{W}$ group. None of the differences between the two groups were significant $(p=0.51)$. Sealing pressure was slightly, but not significantly, higher in the $\mathrm{W}$ group than in the $\mathrm{C}$ group (W group 22.6 $\pm 6.1 \mathrm{~cm} \mathrm{H}_{2} \mathrm{O} ; \mathrm{C}$ group 20.7 $\pm 6.1 \mathrm{~cm} \mathrm{H} 20 ; p=0.15)$.

Conclusions: Prewarming of the i-gel to $42^{\circ} \mathrm{C}$ did not increase the success rate of insertion, nor did it significantly increase sealing pressure in anaesthetised, non-paralysed patients. Our data suggest that we can keep the i-gel at room temperature for emergency airway management for non-paralysed, sedated patients. Trial registration number: University Medical Information Network, Japan 000012287.

\section{INTRODUCTION}

The supraglottic airway device, i-gel (i-gel: Intersurgical, Wokingham, UK), is a singleuse supraglottic device (SGD) with a gel-like cuff and reported to be useful for airway management under general anaesthesia or during resuscitation. ${ }^{1}$

\section{Strengths and limitations of this study}

- A previous study revealed that prewarming the supraglottic device i-gel to $42^{\circ} \mathrm{C}$ facilitated the insertion efficacy under muscle relaxation in anaesthetised, paralysed patients. However, the utility of prewarming of i-gel for patients in non-paralysed, sedated patients has not been validated as yet.

- Prewarming of the i-gel did not facilitate insertion efficacy such as insertion success rate or sealing pressure in non-paralysed, sedated patients.

- Our result suggests that we can keep the i-gel at room temperature for emergent airway management in non-paralysed patients.

- Our randomised prospective study is performed only in one hospital, large-scale study may be needed in the future.

The i-gel is composed of a thermoplastic elastomer which is suggested to fit the laryngeal structure by body temperature exposure. ${ }^{3}$ However, a previous study in which i-gel was prewarmed to $37^{\circ} \mathrm{C}$ did not demonstrate any significant difference in sealing pressure. ${ }^{4}$ We considered that i-gel prewarmed to $37^{\circ} \mathrm{C}$ may be cooled during the insertion process and that insertion and higher prewarming temperature could help the cuff exert a higher sealing pressure. We previously reported significant differences in sealing pressure when the i-gel was prewarmed to $42^{\circ} \mathrm{C}$ under muscle relaxation. ${ }^{5}$

As i-gel is used not only under muscle relaxant contexts but also without muscle relaxation in non-paralysed, sedated or cardiopulmonary suppressed patients, we hypothesised that evaluating the prewarming effect in nonparalysed patients preserving spontaneous ventilation would be informative.

Accordingly, the present study was performed to investigate this hypothesis by 
comparing airway-sealing pressure between i-gel devices prewarmed to $42^{\circ} \mathrm{C}$ and those kept at room temperature (approximately $23^{\circ} \mathrm{C}$ ) in non-paralysed, sedated patients.

\section{METHODS}

From November 2013 to February 2014, 74 patients aged 20-85 years who were to undergo general anaesthesia (maintaining spontaneous ventilation) in the supine position were assigned at random by using the envelope method to one of the two groups: i-gel prewarmed to $42^{\circ} \mathrm{C}$ (W group; 37 patients) and i-gel kept at room temperature (C group; 37 patients). Exclusion criteria included difficult airway such as mouth opening restriction and any contraindication for the use of SGDs (eg, morbid obesity (body mass index, >35), gastrooesophageal reflux and previous upper abdominal surgery) or a recent history (within 7 days) of upper respiratory tract infection. ${ }^{4}$

Routine monitoring of blood pressure, heart rate, ECG, percutaneous oxygen saturation and end-tidal carbon dioxide tension was performed. Without any premedication, propofol $1-2 \mathrm{mg} / \mathrm{kg}$ and fentanyl 1.0 $2.0 \mu \mathrm{g} / \mathrm{g}$ were administered to patients. Doses of sedatives and analgesics were limited so as to maintain spontaneous ventilation to a certain extent. In case of loss of respiratory arrest, the anaesthesiologist performed mask ventilation until the recovery of spontaneous ventilation. The i-gel was warmed to $42^{\circ} \mathrm{C}$ in a heating cabinet with an automatic temperature control for $30 \mathrm{~min}$ before use in the $\mathrm{W}$ group. The time from i-gel delivery from the heating cabinet to insertion into the mouth is approximately $30-60 \mathrm{~s}$. The approximate temperature of the i-gel was $37-39^{\circ} \mathrm{C}$ at the time of insertion, which was measured in the preliminary study. On the basis of this preliminary study, we decided the prewarming to $42^{\circ} \mathrm{C} .{ }^{5}$ For the $\mathrm{C}$ group, i-gel was stored at room temperature (approximately $23^{\circ} \mathrm{C}$ ). A thermometer was used to measure the temperature of the heating cabinet directly. The decision of whether to use a size 3 or 4 i-gel was based on the patient's body weight, as per the manufacturer's instructions. The anaesthesiologist made size determinations for patients weighing $50-60 \mathrm{~kg}$ (ie, between sizes 3 and 4). Sealing pressure was measured after insertion of i-gel with the indicator attached to the anaesthesia machine. Successful insertion was confirmed by bilateral chest wall movement, auscultation and normal capnograms; a sealing pressure of $>15 \mathrm{~cm} \mathrm{H}_{2} \mathrm{O}$ was considered a successful insertion. In case of failed ventilation, an insertion trial was immediately performed, and the number of insertion attempts was recorded. However, if the third attempt failed, the trial was recorded as a failure, and airway management with the LMA-ProSeal was performed. Sealing pressure was compared in successful cases between the $\mathrm{W}$ and $\mathrm{C}$ groups.

Following successful ventilation, anaesthesia was maintained with inhalation of sevoflurane and 33-40\% nitrous oxide in oxygen in order to maintain spontaneous ventilation. Patients were extubated postoperatively, and hoarseness and pharyngeal pain after arousal were assessed by non-blinded anaesthesiologists.

Statistical analysis was performed with JMP 11 (SAS Institute Inc, Cary, North Carolina, USA). The $\chi^{2}$ test and Mann-Whitney $\mathrm{U}$ test were used for data pertaining to patient characteristics. The $\chi^{2}$ test was used for the number of insertion attempts and hoarseness and pharyngeal pain incidents. The Mann-Whitney $U$ test was used to compare sealing pressure. Data are presented as mean \pm SD with $95 \%$ CIs. p Value $<0.05$ was considered statistically significant.

With respect to sample size, the incidence of successful i-gel insertions (sealing pressure $>15 \mathrm{~cm} \mathrm{H}_{2} \mathrm{O}$ on first insertion) in a non-warming preliminary trial in the previous study with muscle relaxation was approximately $50 \%$. As such, we hypothesised that prewarming i-gel would increase the successful insertion rate to $80 \% .^{5}$ To detect this difference with $80 \%$ power at a $5 \%$ significance level, 36 patients would be necessary in each group. Therefore, we planned to recruit 37 patients for each group to adjust for missing data.

\section{RESULTS}

Patient characteristics are shown in table 1 . None of the following parameters differed significantly between the W and C groups: age, sex, body weight, height, body mass index, duration of surgery, duration of anaesthesia, Mallampati score and i-gel size used.

\section{Number of attempts to successful insertion and sealing pressure}

The number of insertion attempts was one for 35 cases and two for 2 cases in the $\mathrm{W}$ group, and one for 35 cases and two for 1 case in the $\mathrm{C}$ group. There was also one failure case in the $\mathrm{C}$ group. The number of successful ventilations in the first trial did not significantly differ between the $\mathrm{W}$ and $\mathrm{C}$ groups $(\mathrm{p}=0.51)$. After successful insertion, the sealing pressure was slightly, but not significantly, higher in the $\mathrm{W}$ group than in the $\mathrm{C}$ group (W group $22.6 \pm 6.1 \mathrm{~cm} \mathrm{H}_{2} \mathrm{O} ; \quad \mathrm{C}$ group $20.7 \pm 6.1 \mathrm{~cm} \mathrm{H}_{2} \mathrm{O} ; \mathrm{p}=0.15$; table 2).

\section{Incidence of hoarseness and pharyngeal pain after general anaesthesia}

Hoarseness was not seen in either group. However, one patient each in both groups experienced pharyngeal pain, although the incidence of these events did not significantly differ between the two groups (table 2).

\section{DISCUSSION}

The pharyngeal sealing pressure, also known as leak pressure, is a measure of how well an SGD seals the laryngeal structure. A higher sealing pressure is an indicator of how well a device might perform during controlled ventilation. Moreover, the i-gel has already been 
Table 1 Patient characteristics

\begin{tabular}{|c|c|c|c|}
\hline & $\begin{array}{l}\text { C group } \\
N=37\end{array}$ & $\begin{array}{l}\text { W group } \\
N=37\end{array}$ & p Value \\
\hline Age & $55.0 \pm 16.7$ & $56.5 \pm 16.0$ & 0.34 \\
\hline Gender (male/female) & $22 / 15$ & $18 / 19$ & 0.48 \\
\hline Body weight (kg) & $60.5 \pm 10.9$ & $59.7 \pm 14.9$ & 0.39 \\
\hline Height (cm) & $162.9 \pm 8.7$ & $161.7 \pm 9.4$ & 0.27 \\
\hline BMI $\left(\mathrm{kg} / \mathrm{m}^{2}\right)$ & $22.7 \pm 3.0$ & $22.7 \pm 4.2$ & 0.39 \\
\hline Duration of surgery (min) & $132.8 \pm 65.9$ & $136.9 \pm 60.2$ & 0.42 \\
\hline Duration of anaesthesia (min) & $84.5 \pm 55.8$ & $87.2 \pm 52.9$ & 0.39 \\
\hline ASA $1 / 2 / 3 / 4$ & $27 / 4 / 6 / 0$ & $22 / 10 / 5 / 0$ & 0.20 \\
\hline Mallampati score $1 / 2 / 3 / 4$ & $32 / 2 / 3 / 0$ & $32 / 5 / 0 / 0$ & 0.11 \\
\hline i-gel size $3 / 4$ & $14 / 23$ & $19 / 18$ & 0.34 \\
\hline
\end{tabular}

Data are presented as mean \pm SD or number of patients. No differences were observed between the two groups.

$\mathrm{C}$ group: i-gel kept at room temperature; $\mathrm{W}$ group: i-gel prewarmed to $42^{\circ} \mathrm{C}$.

ASA, American Society of Anesthesiologists; BMI, body mass index.

shown to exhibit better airway-sealing pressure than conventional SGDs. ${ }^{1}$

Previous reports have suggested that the thermoplastic nature of the material from which the i-gel cuff is manufactured may conform to the laryngeal anatomy as it approaches body temperature. ${ }^{12}$ The sealing pressure of i-gel is suggested to improve over time, which might be due to the thermoplastic property of the cuff which may form a more efficient seal around the larynx after warming to body temperature. ${ }^{6} 7$ These reports noted that the sealing pressure appeared to improve over time, suggesting that the i-gel formed a more efficient seal around the larynx after warming to body temperature. In a previous study which used muscle relaxants, the sealing pressure was higher and leak volume smaller after prewarming the i-gel to $42^{\circ} \mathrm{C}^{5}$

The hypothesis tested in this study was that prewarming of i-gel to $42^{\circ} \mathrm{C}$ would enable the cuff to fit the pharyngeal structure more quickly than if it was stored at room temperature in both non-paralysed, sedated patients. However, we found that the warmed i-gel did not significantly increase successful airway management with a high sealing pressure, in the absence of muscle relaxants. One possible reason is the administration of muscle relaxants which may be attributed to changes in the pharyngeal space. ${ }^{8}$ Since muscle relaxants reduce the pharyngeal space and occasionally collapse the upper airway, the fit of the i-gel might be partially augmented by muscle relaxation. ${ }^{89}$ It may be worth evaluating the effects of muscle relaxants on the insertion success rate and sealing pressure of i-gel in a future study.

SGDs are suited for difficult airway management, especially in a 'cannot intubate, cannot ventilate' situation. ${ }^{10}$ Furthermore, SGDs are used in emergent airway management during resuscitation or emergent respiratory suppression. ${ }^{11}$ For example, the sedation guidelines of the American Society of Anesthesiologists indicate that SGDs are useful for airway rescue in oversedated patients. ${ }^{12}$ Furthermore, airway management is considered as an essential element of both in-hospital and out-of-hospital cadiopulmonary resuscitation. Tracheal intubation is the most widely used method for airway management, but is considered difficult for occasional users. ${ }^{13}$ The AHA-ACLS guidelines emphasise continuous chest compression, and avoiding interruptions as much as possible, even for airway management. ${ }^{14}$ However, the guidelines do not recommend tracheal intubation for all rescuers, but rather suggest SGDs as alternatives. ${ }^{15}$ In emergent situations, such as oversedation or resuscitation, patients are not paralysed by muscle relaxants. Our data suggest that prewarming of i-gel is not needed for emergent airway management for non-paralysed patients.

This study has several limitations. First, we performed the power analysis based on a previous study with a

Table 2 Comparison of factors related to airway management between the prewarmed and control groups

\begin{tabular}{|c|c|c|c|}
\hline & $\begin{array}{l}C \text { group } \\
N=37\end{array}$ & $\begin{array}{l}\text { W group } \\
N=37\end{array}$ & p Value \\
\hline Number of attempts required for successful ventilation $1 / 2 / 3 /$ fail & $35 / 1 / 0 / 1$ & $35 / 2 / 0 / 0$ & 0.51 \\
\hline Sealing pressure on successful ventilation $\left(\mathrm{cm} \mathrm{H}_{2} \mathrm{O}\right)$ & $20.7 \pm 6.1$ & $22.6 \pm 6.1$ & 0.15 \\
\hline Number of patients with hoarseness & 0 & 0 & 1.00 \\
\hline Number of patients with pharyngeal pain & 1 & 1 & 1.00 \\
\hline
\end{tabular}


muscle relaxant. Power analysis based on without muscle relaxation may provide more practical number. The study may be underpowered as the power analysis was based on a previous study using a muscle relaxant, and the fit of the i-gel might be partially augmented by muscle relaxation. Also, the number of additional cases for missing cases may be relatively small. Second, sealing pressure was measured only once immediately after insertion and sealing may have improved over time. Subsequent sealing pressure monitoring may clarify the effect of i-gel prewarming. Third, as this study was conducted at a single institute, a multicentre study or a meta-analysis would clarify the utility of prewarming of i-gel. Fourth, we did not fix the dose of anaesthetic drugs which may yield a non-blinded bias.

In conclusion, we found that the prewarmed i-gel did not provide a higher success rate for insertion or higher sealing pressure in non-paralysed, sedated patients who were not treated with muscle relaxants, as compared with i-gel kept at room temperature.

Contributors NK designed the study, analysed the data and wrote the manuscript. IN designed and conducted the study. ST conducted the study and analysed the data. TM designed the study and wrote the manuscript.

Funding Financial support for the study was provided by the authors' institutions.

Competing interests None.

Patient consent Obtained.

Ethics approval Hokusetsu General Hospital Ethical Committee.

Provenance and peer review Not commissioned; externally peer reviewed.

Data sharing statement No additional data are available.

Open Access This is an Open Access article distributed in accordance with the Creative Commons Attribution Non Commercial (CC BY-NC 4.0) license, which permits others to distribute, remix, adapt, build upon this work noncommercially, and license their derivative works on different terms, provided the original work is properly cited and the use is non-commercial. See: http:// creativecommons.org/licenses/by-nc/4.0/

\section{REFERENCES}

1. Janakiraman $C$, Chethan $D B$, Wilkes $A R$, et al. A randomised crossover trial comparing the i-gel supraglottic airway and classic laryngeal mask airway. Anaesthesia 2009;64:674-8.

2. Russo SG, Cremer S, Eich $\mathrm{C}$, et al. Magnetic resonance imaging study of the in vivo position of the extraglottic airway devices i-gel ${ }^{\mathrm{TM}}$ and LMA-Supreme ${ }^{\mathrm{TM}}$ in anaesthetized human volunteers. $\mathrm{Br} \mathrm{J}$ Anaesth 2012;109:996-1004.

3. Levitan RM, Kinkle WC. Initial anatomic investigations of the I-gel airway: a novel supraglottic airway without inflatable cuff. Anaesthesia 2005;60:1022-6.

4. Nishiyama T, Kohno Y, Kim HJ, et al. The effects of prewarming the l-gel on fitting to laryngeal structure. Am J Emerg Med 2012;30:1756-9.

5. Komasawa N, Nishihara I, Tatsumi S, et al. Pre-warming i-gel® to $42^{\circ} \mathrm{C}$ facilitates successful insertion and ventilation efficacy with muscle relaxation: a randomized study. J Clin Anesth 2014;26:663-7.

6. Gabbott DA, Beringer R. The iGEL supraglottic airway: a potential role for resuscitation? Resuscitation 2007;73:161-2.

7. Theiler LG, Kleine-Brueggeney M, Kaiser D, et al. Crossover comparison of the laryngeal mask supreme and the i-gel in simulated difficult airway scenario in anesthetized patients. Anesthesiology 2009;111:55-62.

8. Keller C, Brimacombe J. Influence of neuromuscular block, mode of ventilation and respiratory cycle on pharyngeal mucosal pressures with the laryngeal mask airway. Br J Anaesth 1999;83:480-2.

9. Ikeda $\mathrm{A}$, Isono $\mathrm{S}$, Sato $\mathrm{Y}$, et al. Effects of muscle relaxants on mask ventilation in anesthetized persons with normal upper airway anatomy. Anesthesiology 2012;117:487-93.

10. Combes X, Le Roux B, Suen P, et al. Unanticipated difficult airway in anesthetized patients: prospective validation of a management algorithm. Anesthesiology 2004;100:1146-50.

11. Komasawa N, Ueki R, Itani M, et al. Validation of the Pentax-AWS Airway Scope Utility as an intubation device during cardiopulmonary resuscitation on the ground. J Anesth 2010;24:582-6.

12. American Society of Anesthesiologists Task Force on Sedation and Analgesia by Non-Anesthesiologists. Practice guidelines for sedation and analgesia by non-anesthesiologists. Anesthesiology 2002;96:1004-17.

13. Kohama H, Komasawa N, Ueki R, et al. Comparison of Supreme® and Soft Seal® laryngeal masks for airway management during cardiopulmonary resuscitation in novice doctors: a manikin study. $J$ Anesth 2011;25:98-103.

14. Neumar RW, Otto CW, Link MS, et al. Part 8: adult advanced cardiovascular life support: 2010 American Heart Association Guidelines for Cardiopulmonary Resuscitation and Emergency Cardiovascular Care. Circulation 2010;122:S729-67.

15. Komasawa N, Ueki R, Yamamoto N, et al. Comparison of air-Q® and Soft Seal® laryngeal mask for airway management by novice doctors during infant chest compression: a manikin study. Resuscitation 2012;83:365-8. 